\title{
The global accretion rate of extraterrestrial materials in the last glacial period estimated from the abundance of micrometeorites in Antarctic glacier ice
}

\author{
Toru Yada ${ }^{1,2 *}$, Tomoki Nakamura ${ }^{1}$, Nobuo Takaoka ${ }^{1}$, Takaaki Noguchi $^{3}$, Kentaro Terada $^{4}$, Hajime Yano $^{5}$, \\ Takakiyo Nakazawa ${ }^{6}$, and Hideyasu Kojima ${ }^{7}$

\begin{abstract}
${ }^{1}$ Department of Earth and Planetary Sciences, Graduate School of Sciences, 33 Kyushu University, 6-10-1 Hakozaki, Fukuoka 812-8581, Japan ${ }^{2}$ Department of Earth and Planetary Science, Graduate School of Science, the University of Tokyo, 7-3-1 Hongo, Bunkyo-ku, Tokyo 113-0033, Japan ${ }^{3}$ Department of Minerals and Biological Sciences, Ibaraki University, Bunkyo 2-1-1, Mito, Ibaraki 310-8512, Japan

${ }^{4}$ Department of Earth and Planetary Systems Science, Graduate School of Science, Hiroshima University, Higashi-Hiroshima 739-8526, Japan

${ }^{5}$ Department of Planetary Science, Institute of Space and Astronautical Science, Japan Aerospace Exploration Agency, 3-1-1 Yoshinodai, Sagamihara, Kanagawa 229-8510, Japan

${ }^{6}$ Center of Atmospheric and Oceanic studies, Graduate School of Science, Tohoku University, Aoba-ku, Sendai 980-8578, Japan

${ }^{7}$ National Institute of Polar Research, 1-9-10 Kaga, Itabashi-ku, Tokyo 173-8515, Japan
\end{abstract}

(Received April 11, 2003; Revised December 26, 2003; Accepted December 29, 2003)

\begin{abstract}
The accretion rate of micrometeorites in the last glacial period was estimated from the concentrations of micrometeorites in the blue ice around the Yamato Mts. in Antarctica. The samples from this study were collected from the five sampling points (M03, K02, K11, J09 and J10) in the blue ice. The blue ice was melted and filtered, and the micrometeorites were handpicked from the collected "glacial sands". The weight of the micrometeorites in the blue ice was estimated from the abundance of recovered micrometeorites and the solar noble gas concentrations in the "residue" after handpicking. The age of the blue ice from the K area was estimated to be $27-33 \mathrm{kyr}$ before present based on oxygen isotope data. The estimated accretion rate to the whole Earth ranges from $5300 \times 10^{3} \mathrm{~kg} / \mathrm{a}$ to $16000 \times 10^{3} \mathrm{~kg} / \mathrm{a}$. However, the lower end of this range probably represents lower limits due to possible loss of solar noble gases during long residence in the glacier ice. Hence, we estimate that the accretion rate of micrometeorites $27-33 \mathrm{kyr}$ before present to be in the range between $(11000 \pm 6600) \times 10^{3} \mathrm{~kg} / \mathrm{a}$ and $(16000 \pm 9100) \times 10^{3} \mathrm{~kg} / \mathrm{a}$. These results, as well as the other estimates, suggest that the accretion rate of micrometeorites in the last glacial period was comparable to that in the present.
\end{abstract}

Key words: Micrometeorite, accretion rate, Antarctica, last glacial periods, noble gas, interplanetary dust particle.

\section{Introduction}

The accretion rate of extraterrestrial material to the Earth is a fundamental parameter that helps to clarify the interaction of the extraterrestrial and terrestrial environments. The influx of interplanetary dust to the Earth at present has been estimated as $(40000 \pm 20000) \times 10^{3} \mathrm{~kg} / \mathrm{a}$ based on the density of hypervelocity impact craters on the surface of the Long Duration Exposure Facility (LDEF), which orbited Earth at 330-480 km for 5.77 years (Love and Brownlee, 1993). This mass influx of interplanetary dust is at least 100 times larger than the annual influx of meteorites $\left(\sim 200 \times 10^{3} \mathrm{~kg} / \mathrm{a}\right.$ by Wetherill (1976); $(2.9-7.3) \times 10^{3} \mathrm{~kg} / \mathrm{a}$ by Bland et al. (1996)). Thus, the accretion rate of interplanetary dust dominates that of extraterrestrial materials. The accretion rate of interplanetary dust in the past provides a constraint on abundances of interplanetary dust at $1 \mathrm{AU}$. For example, Grün et al. (1985) predicted that the flux of interplanetary dust at $1 \mathrm{AU}$ is increasing with time, based on an orbital

*Present address; Laboratory for Space Sciences, CB 1105, Physics Department, Washington University, 1 Brookings Drive, St. Louis, MO 63130-4899, USA.

Copy right(c) The Society of Geomagnetism and Earth, Planetary and Space Sciences (SGEPSS); The Seismological Society of Japan; The Volcanological Society of Japan; The Geodetic Society of Japan; The Japanese Society for Planetary Sciences; TERRAPUB evolution calculation considering collisional destruction between dust grains in interplanetary space. Accretion rates in the past have been estimated from concentrations of ${ }^{3} \mathrm{He}$ in deep-sea sediments $\left(10^{7}-10^{8} \mathrm{~kg} / \mathrm{a}\right.$ by Parkin and Tilles, $1968 ; 400 \times 10^{3} \mathrm{~kg} / \mathrm{a}$ by Takayanagi and Ozima, 1987), and from Os and Ir concentrations in the deep-sea sediments $\left((30000 \pm 15000) \times 10^{3} \mathrm{~kg} / \mathrm{a}\right.$ by Peucker-Ehrenbrink and Ravizza, 2000). A comprehensive review of the accretion rate studies is provided in the appendix of Peucker-Ehrenbrink (1996).

Because of their pristine conditions, micrometeorites, which are melted or unmelted extraterrestrial grains with sizes between $100 \mu \mathrm{m}$ and a few mm, have been collected from Antarctic ice and snow and are an important source of extraterrestrial material. From the dawn of the scientific research in Antarctica, micrometeorites were collected from Antarctic snow (Nishibori and Ishizaki, 1959; Shima and Yabuki, 1968), and later from ice cores (Tazawa and Fujii, 1987; Yiou and Raisbeck, 1987; Yiou et al., 1989), moraine sand (Koeberl and Hagen, 1989; Harvey and Maurette, 1991) and inland blue ice (Tazawa and Fujii, 1987; Zolensky et al., 1989). Yiou et al. (1989) estimated the accretion rate of cosmic spherules (i.e., melted micrometeorites) to be $\sim 1500 \times 10^{3} \mathrm{~kg} / \mathrm{a}$ based on their concentration in the Dome $\mathrm{C}$ ice core. The first large-scale sampling of 


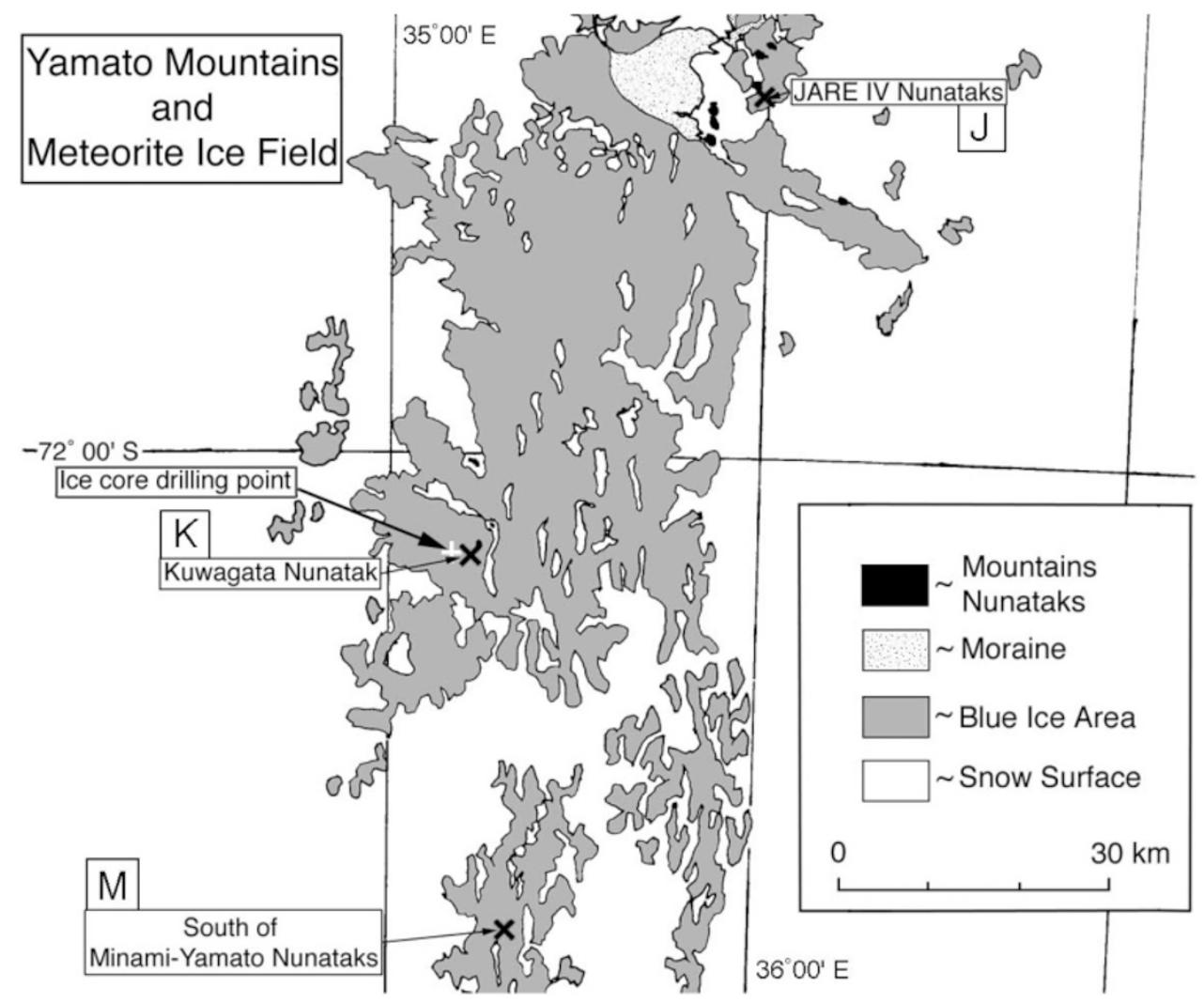

Fig. 1. Area map of blue ice fields around Yamato Mts. in East Antarctica. A total of $4000 \mathrm{~km}^{2}$ of blue ice fields are distributed around Yamato Mts. In 1998, the AMMs collection was carried out in three areas of the blue ice field: South of Minami-Yamato Nunataks (M), Kuwagata Nunatak (K) and JARE IV Nunataks (J). The white cross marks the point where an ice core was drilled in 1983.

Antarctic micrometeorites (hereafter AMMs) was performed by the French research team in Cap-Prudhomme of West Antarctica in 1988 (Maurette et al., 1991), and several subsequent expeditions for AMMs collection were carried out in the same area (Maurette et al., 1994; Engrand and Maurette, 1998; Gounelle et al., 1999). U.S. researchers collected AMMs from the bottom of the water well at the South Pole Station, and the accretion rate of AMMs has been estimated to be $(2700 \pm 1400) \times 10^{3} \mathrm{~kg} / \mathrm{a}$ from AD1000 to AD1500 (Taylor et al., 1998). However, Gounelle et al. (1999) and Maurette et al. (2000) suggested that the collection might be biased due to an inefficient collection method. The Japanese AMM working group also separated AMMs from sediments in the water tank at the Dome Fuji Station recovered by the Japanese Antarctic Research Expedition (JARE) team in 1996 (Nakamura et al., 1999; Noguchi et al., 2000). A largescale sampling of AMMs was performed by the 39th JARE at the inland blue ice area around the Yamato Mts. in 19981999 (Yada and Kojima, 2000). This sampling was the first attempt to perform a large-scale collection of AMMs directly from blue ice in the interior of Antarctica. An AMM sampling was also performed at the blue ice area near the Syowa station in 2000 by the 41st JARE (Iwata and Imae, 2002) using the same method as Yada and Kojima (2000).

In order to better estimate the accretion rate of extraterrestrial materials, we investigated the concentration of AMMs in Antarctic glacier ice collected by the 39th JARE. We tried to recover as many AMMs as possible in order to better understand the chemistry, mineralogy and size distribu- tion of AMMs. We also performed noble gas analyses on the "residue" of glacier sand, from which the AMMs were picked, and estimated the amount of AMMs remaining in the residue using solar $\mathrm{Ne}$ concentrations. Combining the abundance of AMMs recovered by handpicking and those estimated to be remaining in the residue, we calculated a total abundance of AMMs in the blue ice for each sampling point.

\section{Y98 Antarctic Micrometeorite Samples- General Descriptions and Collection Method-}

The samples from the present study were collected at a blue ice area around the Yamato Mts. in Antarctica during the austral summer of 1998 (Yada and Kojima, 2000), and are hereafter, referred to as the Y98 samples. A general description of inland blue ice areas around the Yamato Mts. is shown in Appendix A. The Y98 samples were collected from three different areas among the Yamato blue ice: South of the Minami-Yamato Nunataks (M) area, the Kuwagata Nunatak (K) area and the JARE IV Nunataks (J) area, which are all 30 to $50 \mathrm{~km}$ distant from one to another (Fig. 1).

\subsection{Estimation of the age of the ice in the $K$ area}

The age of the ice was estimated from glaciological data in the $\mathrm{K}$ area. In the blue ice field around Yamato Mts. a $101.4 \mathrm{~m}$ long ice core was recovered at $72^{\circ} 11^{\prime} 13^{\prime \prime} \mathrm{S}$, $35^{\circ} 11^{\prime} 00^{\prime \prime} \mathrm{E}$ in 1983 (Nakawo et al., 1988; Nakazawa et al., 1993; Machida et al., 1996). As shown in Fig. 1, this drilling point is only $\sim 2 \mathrm{~km}$ west-northwest of the $\mathrm{K}$ area in the present study. The oxygen isotopic composition of the an- 

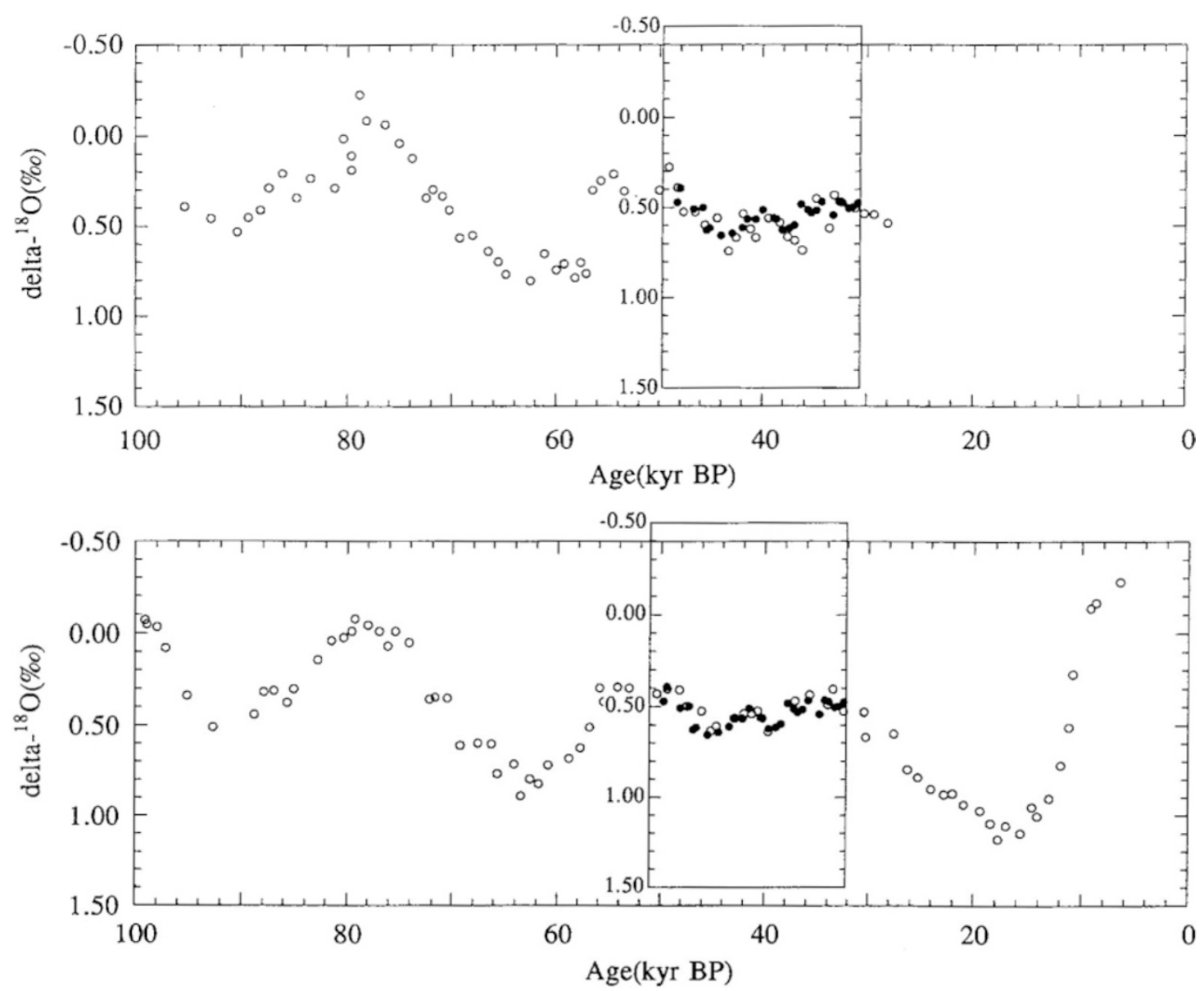

Fig. 2. The fit of the $\delta 18 \mathrm{O}_{\text {atm }}$ variation of the ice core at Yamato Mts. (closed circles) with that of (a) the Vostok station and (b) the GISP2. The precisions of these analyses are $\pm 0.04 \%$ o $(1 \sigma)$. With subtraction of $0.1 \%$ from the Yamato data, the $\delta^{18} \mathrm{O}_{\text {atm }}$ variation of the Yamato ice core corresponds to that from $50 \mathrm{kyr} \mathrm{BP}$ to $31 \mathrm{kyr} \mathrm{BP}$ of the Vostok ice core and from $51 \mathrm{kyr} \mathrm{BP}$ to $32 \mathrm{kyr} \mathrm{BP}$ of the GISP ice core.

cient atmosphere trapped in the ice core was measured with a dry air-extraction system. The experimental procedure is detailed in Nakazawa et al. (1993). In Fig. 2, obtained $\delta^{18} \mathrm{O}_{\text {atm }}$ variations are compared and fit to (a) the data of the Vostok station in Antarctica (Bender et al., 1994) and (b) the data of Greenland glacier (the Greenland Ice Sampling Project 2 (GISP2); Petit et al., 1999). The correspondence of the variation of $\delta^{18} \mathrm{O}_{\text {atm }}$ with age was confirmed in the two ice cores. With a $0.1 \%$ offset in the vertical direction, the $\delta^{18} \mathrm{O}$ variation of the $101.4 \mathrm{~m}$ Yamato Mts.' core fits to that of the Vostok core whose age ranges from $50 \mathrm{kyr}$ before present (BP) to $31 \mathrm{kyr}$ BP (Fig. 2(a)), and it also fits to the Greenland core whose age ranges from $51 \mathrm{kyr}$ BP to $32 \mathrm{kyr} \mathrm{BP}$ (Fig. 2(b)). The $0.1 \%$ offset may be attributable to different standards and mass spectrometers used to make the measurements. Here, we use the Vostok ice core data to estimate the age of the Yamato ice core, because the snow accumulation conditions for the Vostok core should be more similar to those for the Yamato ice core than those for the Greenland ice core. However, the actual snow accumulation age of the blue ice is considered to be $2000-6000$ years older than the age of the air bubbles enclosed in the blue ice. This difference results from the enclose time needed to the air bubbles in the blue ice from the surrounding atmosphere. This occurs at $\sim 120 \mathrm{~m}$ depth from the snow surface and it would take about 2000-6000 years to reach such a snow accumula- tion depth due to small snow accumulation rate in the inland of the Antarctica. In the case of the Vostok core, the difference between the age of the ice and that of the enclosed air was estimated to be $5.35 \pm 0.3 \mathrm{kyr}$ at $110 \mathrm{kyr} \mathrm{BP}$, using $\delta^{15} \mathrm{~N}$ and $\delta^{40} \mathrm{Ar}$ values of trapped gas (Caillon et al., 2001). In addition, the fit is done visually, adding around $1 \mathrm{kyr}$ uncertainty. Therefore, the age of the top of the ice core drilled close to the $\mathrm{K}$ area is estimated to be $27-33 \mathrm{kyr} \mathrm{BP}$.

Based on numerical simulations of ice flow, the age of ice $6 \mathrm{~km}$ away from the $\mathrm{J}$ area has been estimated to be several tens of thousand years BP (Azuma et al., 1985). The age of ice in the $\mathrm{M}$ area has not been determined, but it must be younger than that in the $\mathrm{K}$ area, because the age of blue ice increases with increasing distance from mountains or nunataks (cf. Azuma et al., 1985; see Fig. 1). Consequently, we estimate that the age of the blue ice from which AMMs were collected corresponds to the last glacial period (from $110 \mathrm{kyr}$ to $10 \mathrm{kyr} \mathrm{BP}$ ) and the age increases in the order $\mathrm{M}, \mathrm{K}$ and $\mathrm{J}$. This estimate is consistent with Terada et al. (2001), who reported that average $\mathrm{Mg} / \mathrm{Si}$ ratios of unmelted AMMs decrease from $\mathrm{K}$ to $\mathrm{J}$ samples and the abundance of jarosite, an alteration product in glacial ice, increases from $\mathrm{M}$ to K samples. They suggested that the Mg content of AMMs decreases due to aqueous alteration during their residence in the blue ice. 


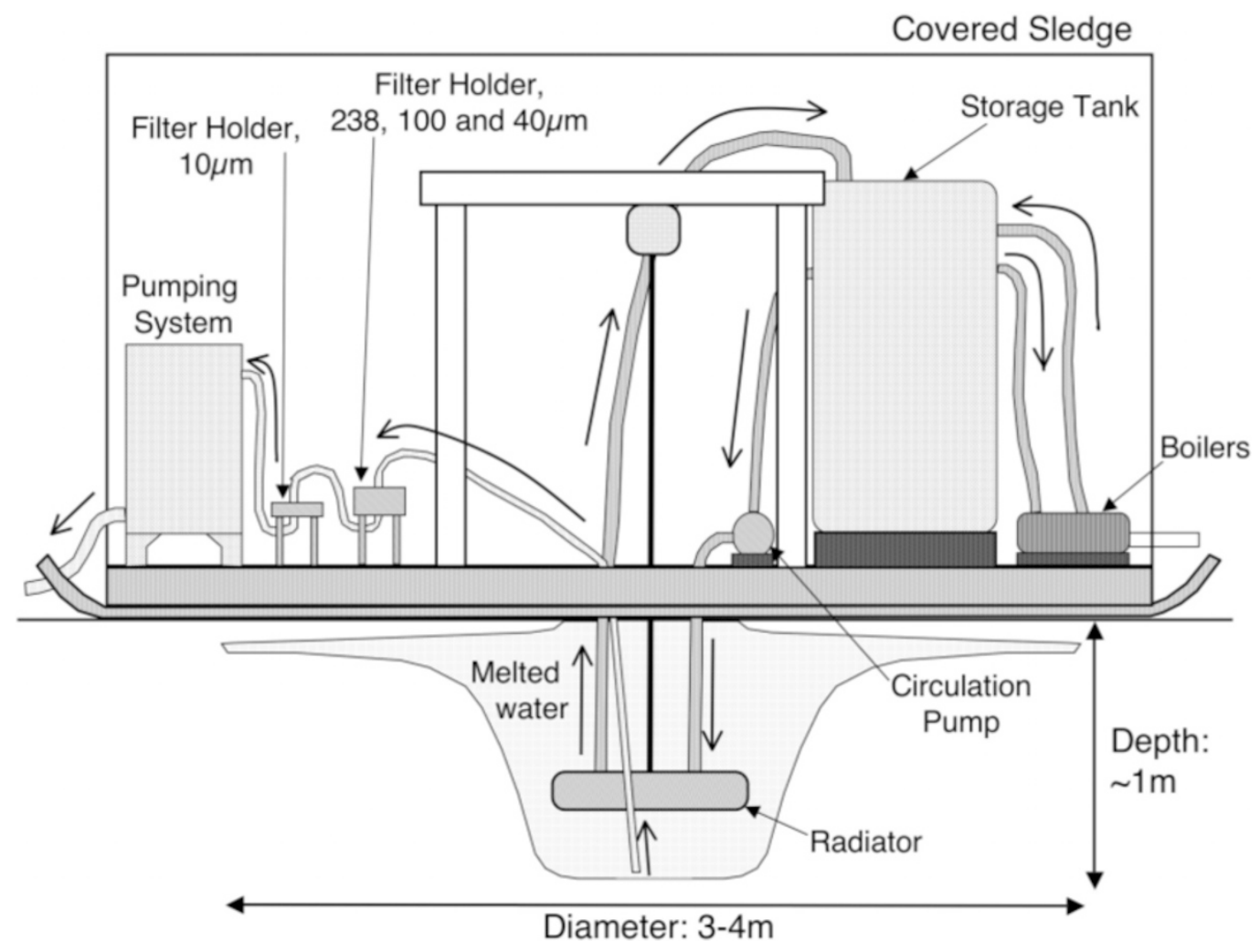

Fig. 3. A schematic diagram of the sampling system used at the blue ice area of the Yamato Mts. in 1998. Glacial ice was heated and melted with a radiator hung in a melted water pond, whose shape was like an "upside down cowboy hat". After the radiator was pulled out of the pond, the melted water was pumped and filtered through a series of stainless-steel meshes with 10, 40, 100 and $238 \mu \mathrm{m}$ openings.

\subsection{A sample collection method and its efficiency}

Sampling was performed at a total of 24 points: three in the $\mathrm{M}$ area, eleven in the $\mathrm{K}$ area and ten in the $\mathrm{J}$ area. The sampling points are designated by the area name followed by the sampling number in each area; e.g., the third point in the $\mathrm{M}$ area is M03. Glacial ice was melted with a radiator, in which warmed non-freezing liquid was circulated. The melted water was pumped up and filtered through a series of sheets of stainless-steel meshes, whose pore sizes were $10 \mu \mathrm{m}, 40 \mu \mathrm{m}, 100 \mu \mathrm{m}$ and $238 \mu \mathrm{m}$, respectively (Fig. 3). The method is detailed in Yada and Kojima (2000). The samples ("glacial sands") are mixtures of particles originally contained within the glacier ice, including AMMs, and terrestrial materials introduced during sample collection. In total, $1.19 \mathrm{~g}$ of particles were collected by melting $34.5 \times 10^{3} \mathrm{~kg}$ of blue ice from 24 points in these three areas. Because of the low pumping speed of the system, only 250 liters of the melted water, corresponding to $10-20 \%$ of the water in the pond, could be filtered in an hour before it began to refreeze. In order to collect particles effectively, the end of the tube in the pond was controlled to sweep all areas of the bottom of the pond during pumping.

The collection efficiency of AMMs is described briefly here. During melting of the glacial ice, the "glacial sand" originally included in the ice descends to the bottom of the pond. Silicate particles of $40 \mu \mathrm{m}$ diameter in water at $5^{\circ} \mathrm{C}$ sink at a speed of $\sim 0.13 \mathrm{~cm} / \mathrm{s}$, so that they reach the bottom of the pond ( $\sim 1 \mathrm{~m}$ depth) within about 15 minutes. Thus, particles larger than $40 \mu \mathrm{m}$ could well precipitate on the bottom of the pond during the sampling procedure. It is ex- pected that silicate particles up to $\sim 900 \mu \mathrm{m}$ in diameter can be recovered with this system; according to Stokes' law, a silicate spherule of $900 \mu \mathrm{m}$ diameter sinks at $58 \mathrm{~cm} / \mathrm{s}$, which corresponds to the actual intake flow speed of water during pumping $(60 \mathrm{~cm} / \mathrm{s})$. This is comparable to the maximum size of AMMs $(\sim 800 \mu \mathrm{m})$ collected at the South Pole water well, in which a larger volume of ice $\left(\sim 5000 \times 10^{3} \mathrm{~kg}\right)$ was melted (Lever et al., 1996; Taylor et al., 1998; Taylor et al., 2000). Hence, the present sampling system is capable of collecting AMMs with sizes from $40 \mu \mathrm{m}$ to $900 \mu \mathrm{m}$ in diameter. Smaller $(<40 \mu \mathrm{m})$ or fluffy AMMs, however, might not be collected, because they are less likely to sink to the bottom of the pond due to convection or turbulence (see details in Terada et al., 2001). Gounelle et al. (1999) and Maurette et al. (2000) suggested the possibility that glacial sand at the bottom of the pond would be re-trapped in the ice due to refreezing of thin layer of water at the bottom of the pond. However, since the bottom water was continuously stirred, this effect would not be important in the present study. Hence, we expect that AMMs with sizes between $\sim 40 \mu \mathrm{m}$ and $900 \mu \mathrm{m}$ were recovered effectively in the present study.

\section{Experimental Methods}

Of the twenty-four Y98 samples, M03, K02, K11, J09, and $\mathrm{J} 10$ were selected for estimation of accretion rates because of their low contamination, as observed under a stereomicroscope. Total weights of these five samples are shown in Table 3. The analytical procedures are shown as a flowchart in Fig. 4. First, candidate AMMs were handpicked from the glacial sand under a stereomicroscope. Particles 


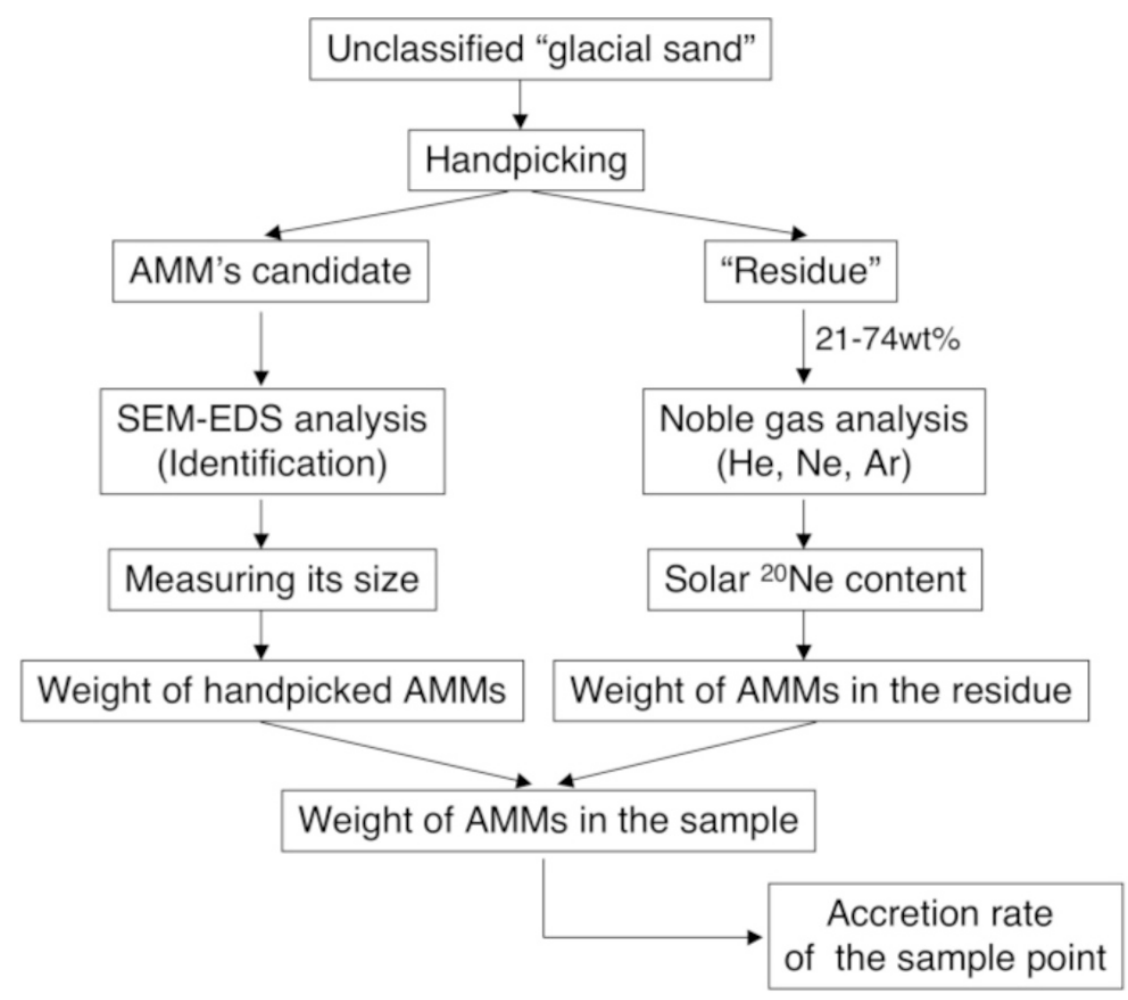

Fig. 4. A flowchart showing sample handling and estimate of the AMMs flux in this study. The weight of AMMs collected at sampling point was determined by a combination of both handpicking and noble gas analysis of residues after handpicking.

Table 1. Number of handpicked AMMs from each sampling point.

\begin{tabular}{lcccccc}
\hline Sampling Point & M03 & K02 & K11 & J09 & J10 & Total \\
\hline Total AMMs & 155 & 251 & 257 & 127 & 152 & 942 \\
Unmelted AMMs & 98 & 152 & 173 & 81 & 87 & 591 \\
(fraction) & $(63 \%)$ & $(61 \%)$ & $(67 \%)$ & $(63 \%)$ & $(57 \%)$ & $(63 \%)$ \\
Spherules & 57 & 99 & 84 & 46 & 65 & 351 \\
S-type spherules & 21 & 44 & 45 & 27 & 40 & 177 \\
G-type spherules & 33 & 49 & 36 & 16 & 22 & 156 \\
I-type spherules & 3 & 6 & 3 & 3 & 3 & 18 \\
\hline
\end{tabular}

in the 10-40 $\mu \mathrm{m}$ size fraction were not handpicked because such small particles were not collected effectively, as discussed previously. However, the contribution of extraterrestrial material to this size fraction is reported to be minor $(<10 \%$ of the total; Love and Brownlee, 1993). For identification of AMMs, the particles were analyzed with a scanning electron microscope equipped with an energy dispersive Xray spectrometer (SEM-EDS). The SEM-EDS mainly used for this study was a JEOL JSM-5800LV, located at the National Institute of Polar Research (NIPR), Japan, which can be operated at a low vacuum for the analysis of samples without conductive coatings. The principles for identification of AMMs are basically the same as those described in Nakamura et al. (1999). For silicate particles, those with major peaks in $\mathrm{Si}, \mathrm{Mg}$ and $\mathrm{Fe}$ and minor peaks in $\mathrm{Al}, \mathrm{Ca}$ and $\mathrm{S}$ were identified as AMMs. This criterion is effective; 27 particles from the Dome Fuji station that were identified as AMMs using these criteria all proved to be extraterrestrial based on the detection of solar-wind related $\mathrm{He}$ and $\mathrm{Ne}$ (Osawa and Nagao, 2002). For iron-oxide spherules, those containing more than a few wt $\% \mathrm{Ni}$ were identified as cosmic spherules. For all identified AMMs, backscattered electron images were recorded. Based on studies of micrometeorites recovered from Greenland and Antarctic glacier ice, AMMs have been divided into four types: irregular-shaped unmelted AMMs, stony (S) type spherules, glassy (G) type spherules and iron (I) type spherules (Maurette et al., 1987; Maurette et al., 1991; Taylor et al., 2000), where S-type and G-type spherules correspond to opaque and transparent silicate spherules, respectively. We also use this classification for the AMMs identified in the present study.

After handpicking AMMs, some AMMs might still remain in the rest of the glacial sand residues. Solar-type noble gases ( $\mathrm{He}$ and $\mathrm{Ne}$ ) have been detected in AMMs (Maurette et al., 1991; Nakamura and Takaoka, 2000; Osawa and Nagao, 2002) and, thus, noble gas contents are expected to be correlated with the AMM contents of the residues. We analyzed $\mathrm{He}, \mathrm{Ne}$ and Ar isotopes in the residues of the 40-100 $\mu \mathrm{m}$ and 100-238 $\mu \mathrm{m}$ fractions with an MM5400 noble gas mass spectrometer installed at Kyushu University; the analytical 


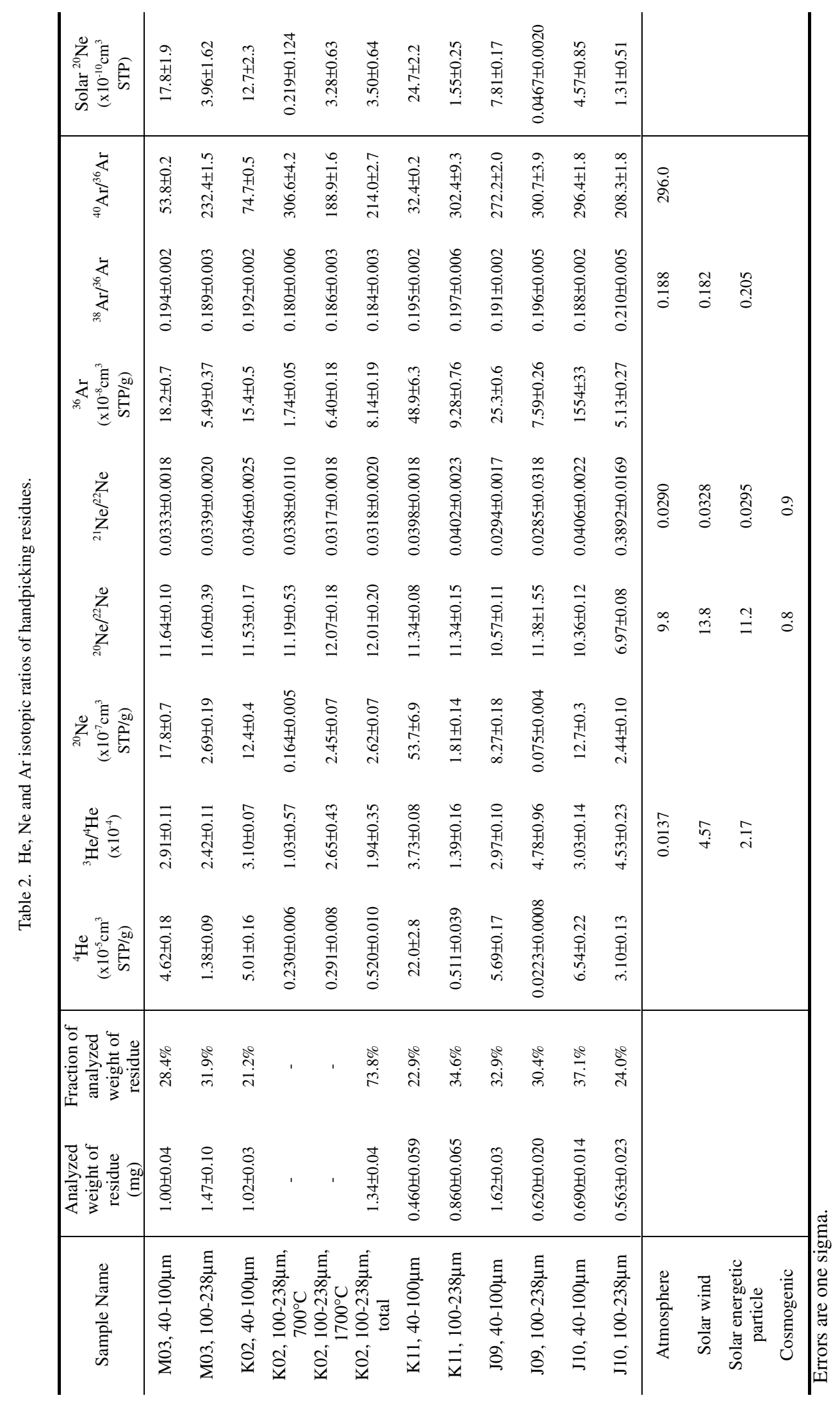



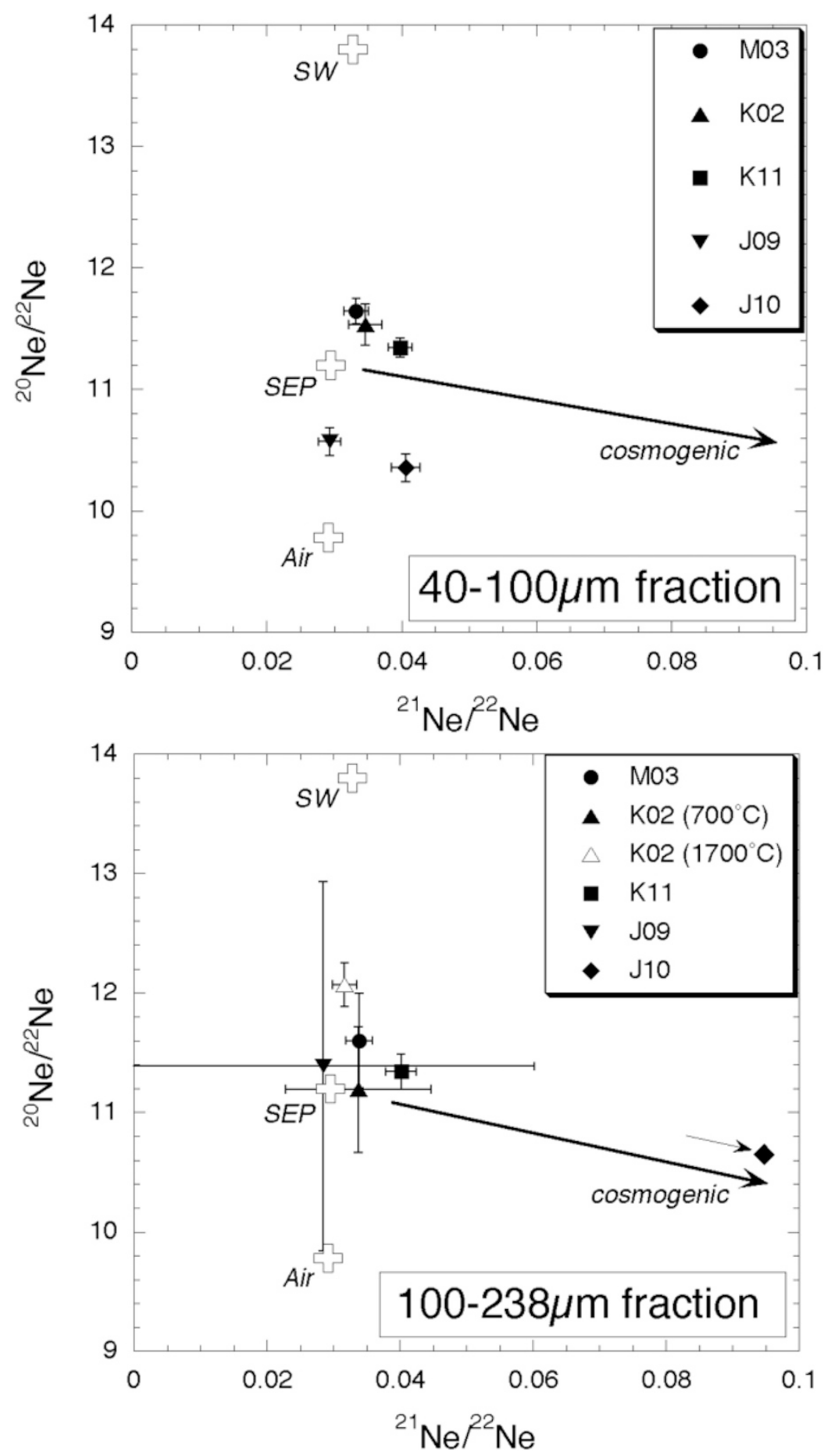

Fig. 5. Neon three-isotope diagrams for residues of the M03, K02, K11, J09 and J10 samples. Error bars are 1 sigma. (a) Data for 40-100 $\mu \mathrm{m}$ fractions. J09 and J10 plot below the mixing line between SEP and a cosmogenic component. (b) Data for 100-238 $\mu$ m fractions. J10 is located outside the graph in the direction of the cosmogenic component.

procedure was described by Nakamura and Takaoka (2000). About 21-74 wt\% of the residues were used for the analyses. Samples were heated at $1700^{\circ} \mathrm{C}$, except for the 100-238 $\mu \mathrm{m}$ fraction of $\mathrm{K} 02$, which was heated in two steps at 700 and $1700^{\circ} \mathrm{C}$.

\section{Results}

The numbers of the various types of AMMs handpicked from the five sampling points are shown in Table 1. These numbers have been revised from those given in Terada et al. (2001), in which the number of I-type spherules (8-43\% of the total spherules) is apparently overestimated compared with previous estimates (1-2\%; Taylor et al., 2000). The ratios of unmelted AMMs to total AMMs do not vary much among sampling points (57-67\%), and are comparable to the result of Maurette et al. (1991), whose ratio of unmelted to the total AMMs for all size fractions is $\sim 54 \%$. Micrographs and EDS spectra of all identified AMMs are available on the web (http://www.gakushuin.ac.jp/amm/).

The results of our noble gas analyses are summarized in 
Table 3. The evaluated weights of AMMs and the calculated accretion rates.

\begin{tabular}{lccccc}
\hline Sampling Point & M03 & K02 & K11 & J09 & J10 \\
\hline Melted ice $\left(10^{3} \mathrm{~kg}\right)$ & 0.91 & 0.90 & 1.86 & 1.11 & 1.01 \\
Total collected glacial sand $(\mathrm{mg})$ & 13.8 & 11.3 & 8.17 & 10.4 & 6.06 \\
Handpicked AMMs $(\mathrm{mg})$ & 0.248 & 0.282 & 0.357 & 0.137 & 0.256 \\
AMMs in residues $(\mathrm{mg})$ & 0.409 & 0.346 & 0.596 & 0.126 & 0.099 \\
AMMs conc. $\left(10^{-10} \mathrm{~g} / \mathrm{g}\right.$ ice) & 7.25 & 6.98 & 5.12 & 2.38 & 3.53 \\
Error & 1.26 & 1.39 & 0.93 & 0.46 & 0.90 \\
Accretion rate $\left(10^{3} \mathrm{~kg} / \mathrm{a}\right)$ & 16000 & 16000 & 11000 & 5300 & 7900 \\
Error & 9300 & 9100 & 6600 & 3100 & 4800 \\
\hline
\end{tabular}

Table 2. The observed helium isotopic ratios indicate that most of the helium in the residues is a mixture of solar energetic particle (SEP) and solar wind (SW) components (Benkert et al., 1993). Smaller size fractions $(40-100 \mu \mathrm{m})$ have higher ${ }^{4} \mathrm{He}$ concentrations and higher ${ }^{3} \mathrm{He} /{ }^{4} \mathrm{He}$ ratios than larger size fractions $(100-238 \mu \mathrm{m})$ in the $\mathrm{M}$ and $\mathrm{K}$ samples. This is probably due to better retention of low energy SW helium in smaller AMMs due to less heating upon atmospheric entry. In the $\mathrm{J}$ samples, however, the smaller size fractions are more contaminated by atmospheric noble gases, possibly caused by alteration of the $\mathrm{J}$ samples in the glacial ice. These samples have the longest residence time in the glacial ice and should have experienced the most severe aqueous alteration, as noted earlier.

The Ne data are shown in Figs. 5(a) and (b). Most Ne isotopic ratios are close to SEP-Ne, except for the 100-238 $\mu \mathrm{m}$ fraction of $\mathrm{J} 10$, which contains a considerable cosmogenic component relative to other samples (Fig. 5(b)). The 40$100 \mu \mathrm{m}$ fractions of the $\mathrm{J}$ samples plot below the mixing line between SEP and the cosmogenic component (Fig. 5(a)), suggesting that they contain some amount of atmospheric $\mathrm{Ne}$.

For the $40-100 \mu \mathrm{m}$ fractions, ${ }^{40} \mathrm{Ar} /{ }^{36} \mathrm{Ar}$ ratios in the $\mathrm{J}$ samples (272-296) are much higher than those in the $M$ and K samples (32-75) and closer to the atmospheric value (296). $\mathrm{J} 10$, in particular, has the highest ${ }^{36} \mathrm{Ar}$ concentration among the all samples and has ${ }^{38} \mathrm{Ar} /{ }^{36} \mathrm{Ar}$ and ${ }^{40} \mathrm{Ar} /{ }^{36} \mathrm{Ar}$ ratios indistinguishable from the atmospheric values. This indicates that atmospheric Ar contamination is more dominant in the $\mathrm{J}$ samples than in the $\mathrm{M}$ and $\mathrm{K}$ samples due to the longer residence of the $\mathrm{J}$ samples in the glacial ice. For the $\mathrm{M}$ and $\mathrm{K}$ samples, ${ }^{40} \mathrm{Ar} /{ }^{36} \mathrm{Ar}$ ratios are higher and closer to the atmospheric value in the 100-238 $\mu \mathrm{m}$ fractions (214-302) than in the 40-100 $\mu \mathrm{m}$ fractions (32-75). This could be due to more severe heating upon atmospheric entry for larger AMMs.

The neon data were mathematically decomposed into solar (solar wind, SW, or solar energetic particles, SEP), cosmogenic (C) and atmospheric (A) components. The obtained concentrations of solar ${ }^{20} \mathrm{Ne}$ were then used to estimate the concentrations of AMMs in the residues. The following isotopic ratios $\left({ }^{20} \mathrm{Ne} /{ }^{22} \mathrm{Ne},{ }^{21} \mathrm{Ne} /{ }^{22} \mathrm{Ne}\right)$ were used for this calculation: $(13.8,0.0328)$ for SW, $(11.2,0.0295)$ for SEP (Benkert et al., 1993), (0.8, 0.9) for cosmogenic Ne (Eugster, 1988) and $(9.80,0.029)$ for atmospheric Ne (Ozima and Podosek, 2002), respectively. When the Ne isotopic ratios plot above the mixing line of SEP and C in Fig. 5, the mea- sured ${ }^{20} \mathrm{Ne}$ concentrations are decomposed into SW, SEP and C. Those that plot below the SEP-C mixing line are decomposed into SEP, A and C. The abundances of solar ${ }^{20} \mathrm{Ne}$ in the residues thus calculated are listed in Table 2. There is a possibility that the measured $\mathrm{Ne}$ in the residues consists of SW, A and C. Our deconvolution assumption should, however, be plausible based on the properties of both the A and SW components. Atmospheric contamination to the AMMs should not result from adsorption onto their surfaces, but from implantation during atmospheric entry and/or incorporation into secondary minerals growing on their surfaces during residence in the blue ice. Both events are surfacerelated, as is SW, which penetrates only several angstroms into exposed rock surfaces (Benkert et al., 1993), in contrast to SEP, which penetrates a few tens of microns into the rock surfaces (Wieler et al., 1987). Thus, the degree of atmospheric contamination to the AMMs might be possibly anti-correlated with the SW components. Based on this assumption, the samples that plot above the SEP-C mixing line should be less contaminated than those that plot under the mixing line.

Based on the solar ${ }^{20} \mathrm{Ne}$ concentrations in the residues deduced above and that in a single AMM particle, we can calculate weights of AMMs in the residues. We assume that noble gases are retained only in unmelted AMMs, because the melted spherules are easily distinguished in the glacial sand and few should be left in the residues. There is an inverse correlation between solar gas concentrations in pulverized meteorite samples and grain sizes (Eberhardt et al., 1965). This is because the solar gases are surface-related and smaller grains have greater surface/volume ratios than large ones. We can therefore assume the same tendency for micrometeorites. Moreover, a smaller interplanetary dust particle will be less heated and thus less degassed than a larger one during atmospheric entry (Nier and Schlutter, 1993). Thus we have to optimize the solar ${ }^{20} \mathrm{Ne}$ concentration of AMMs for each size fraction. In previous work, 22 AMMs of $100-260 \mu \mathrm{m}$ in diameter were analyzed individually with a noble gas mass spectrometer equipped with a laser extraction line, and the average ${ }^{20} \mathrm{Ne}$ concentration of the AMMs was $1.61 \times 10^{-5} \mathrm{~cm}^{3} \mathrm{STP} / \mathrm{g}$ (Osawa and Nagao, 2002). We apply this value for the $100-238 \mu \mathrm{m}$ fraction. Based on the same study, the average of ${ }^{20} \mathrm{Ne}$ concentrations of five AMMs 60 $90 \mu \mathrm{m}$ in diameter is $1.89 \times 10^{-5} \mathrm{~cm}^{3} \mathrm{STP} / \mathrm{g}$, which can be applied for the $40-100 \mu \mathrm{m}$ fractions. The ${ }^{20} \mathrm{Ne}$ concentrations for both size fractions have large deviations because 
the AMMs studied by Osawa and Nagao (2002) have variable ${ }^{20} \mathrm{Ne}$ concentrations. In the present study, we used only the average ${ }^{20} \mathrm{Ne}$ concentrations. Because most $\mathrm{Ne}$ isotopic ratios for individual analysis of AMMs overlapped with SEP within experimental errors (Osawa and Nagao, 2002), we assume that for each size fraction of AMMs all ${ }^{20} \mathrm{Ne}$ consists of the solar components. The estimated abundances of AMMs in the residues are shown in Table 3.

\section{Discussion}

\subsection{Estimation of accretion rate from concentration of} AMMs in blue ice

Based on the concentration of AMMs in the blue ice, the accretion rate of extraterrestrial materials onto the Earth, $F$, is calculated by the following equation,

$$
F=A_{e} \times\left(\frac{m_{c}}{M_{i}} \times f_{s}\right)
$$

where $A_{e}, m_{c}, M_{i}$, and $f_{s}$ represent the total surface area of the Earth $\left(5.1 \times 10^{18} \mathrm{~cm}^{2}\right)$, the gross weight of accumulated AMMs (g), the weight of melted ice (g), and the accumulation rate of snow $\left(\mathrm{g} / \mathrm{cm}^{2} / \mathrm{a}\right)$ for the blue ice of the sampling point at the time of deposition, respectively. Here, $m_{c} / M_{i}$ represents the AMMs concentration in the blue ice (i.e., grams of AMMs in 1 gram of the blue ice) and $\left(m_{c} / M_{i}\right) \times f_{s}$, corresponds to the accumulation rate of AMMs to the Earth's surface in gram per $\mathrm{cm}^{2}$ per year.

The accumulation rate of snow, $f_{s}$, is estimated as follows. Glacier ice now exposed around Yamato Mts. originated from snow accumulated at the upstream area of the glacier flow, located south of the Yamato Mts. The present snow accumulation rate in this area ranges from 3.0 to $10.0 \mathrm{~g} / \mathrm{cm}^{2} / \mathrm{a}$ (NIPR, 1997). As discussed earlier, the ages of the blue ice at the five sampling points are estimated to be from the last glacial period. The snow accumulation rate in the last glacial period $\left(2-3 \mathrm{~g} / \mathrm{cm}^{2} / \mathrm{a}\right)$ was about two thirds of that in the present interglacial period $\left(3-4.5 \mathrm{~g} / \mathrm{cm}^{2} / \mathrm{a}\right)$ at the top of the Dronning Maud Land ice cap, the upstream region of the Yamato blue ice areas (Watanabe et al., 1999a,b). Therefore, the snow accumulation rate for the blue ice at each sampling point is estimated to be within $2.0-6.7 \mathrm{~g} / \mathrm{cm}^{2} / \mathrm{a}$. Here, we apply an average value of $4.4 \pm 2.4 \mathrm{~g} / \mathrm{cm}^{2} / \mathrm{a}$ as $f_{s}$ for each sampling point. The weight of melted ice at each sampling point, $M_{i}$, is shown in Table 3 (10\% errors are assumed). These values are revised slightly from those in Yada and Kojima (2000) because the latter ignored the effect of air bubbles in blue ice on the density. Note that deformation of the ice due to compaction and ice flow would not affect this estimate of the AMMs accumulation rate $F$, because $m_{c} / M_{i}$ should be constant during ice deformation.

The apparent volume of each identified AMM was estimated by assuming a spherical shape, whose radius is approximated by the arithmetic average of the major and minor axes of the AMM measured on the SEM image. The densities of the AMMs are $3.0 \mathrm{~g} / \mathrm{cm}^{3}$ for S- and G-type spherules (i.e., approximate density for mafic silicate minerals), $5.0 \mathrm{~g} / \mathrm{cm}^{3}$ for I-type spherules (i.e., approximate density for iron oxide) and $1.0 \mathrm{~g} / \mathrm{cm}^{3}$ for unmelted AMMs. This last value was estimated from the total weights and apparent volumes of 15 and 30 unmelted AMMs measured together using an ultra-microbalance and SEM images. Errors for the weights of handpicked AMMs are $32 \%$, resulting from a $10 \%$ error for both the diameter and density of each particle.

The total weight of AMMs in each sampling point, $m_{c}$, is calculated from the weight of handpicked AMMs, estimated above, and that in the residues estimated from solar $\mathrm{Ne}$ concentrations. The results are summarized in Table 3. Finally, the accretion rate of AMMs, $F$, is determined for each sampling point and is shown in Table 3. The estimated accretion rates are $(16000 \pm 9300) \times 10^{3} \mathrm{~kg} / \mathrm{a}$ for M03, $(16000 \pm$ $9100) \times 10^{3} \mathrm{~kg} / \mathrm{a}$ for K02, $(11000 \pm 6600) \times 10^{3} \mathrm{~kg} / \mathrm{a}$ for K11, $(5300 \pm 3100) \times 10^{3} \mathrm{~kg} / \mathrm{a}$ for J09 and $(7900 \pm 4800) \times 10^{3} \mathrm{~kg} / \mathrm{a}$ for J10 (Table 3).

\subsection{Comparison of accretion rates from this study with those in the literature}

5.2.1 The accretion rate in the last glacial period This study is the first attempt to estimate the accretion rate of extraterrestrial materials using handpicking of AMMs combined with noble gas analysis. As shown in Table 3, the abundances of AMMs in the residues are greater than the handpicked AMMs in the M and K samples and are not negligible in the $\mathrm{J}$ samples. This indicates that considerable numbers of AMMs are missed in handpicking and suggests that noble gas analysis of a residue after handpicking is necessary for determining the total weight of AMMs in the sample. The estimated weights of AMMs in the J09 and J10 residues $(\sim 0.1 \mathrm{mg})$ are much lower than those of the $\mathrm{M}$ and $\mathrm{K}$ samples $(0.35-0.60 \mathrm{mg})$. Moreover, $\mathrm{Ne}$ isotope data for 40-100 $\mu \mathrm{m}$ fractions of J09 and J10 samples show higher levels of atmospheric contamination (Fig. 5(a)). As pointed out before, J samples may have lost some part of their solar gases and acquired atmospheric gases due to aqueous alteration during long residence in the glacier ice. Hence, the obtained accretion rates of AMMs for J09 and J10 must be considered lower limits.

The estimated accretion rate of AMMs for the K area, at $27-33 \mathrm{kyr} \mathrm{BP}$, is in the range between $(11000 \pm 6600) \times$ $10^{3} \mathrm{~kg} / \mathrm{a}$ and $(16000 \pm 9100) \times 10^{3} \mathrm{~kg} / \mathrm{a}$. The age of blue ice in M03 is unknown but is younger than that of the $\mathrm{K}$ area, and the estimated accretion rate for the $\mathrm{M}$ area, $(16000 \pm 9300) \times 10^{3} \mathrm{~kg} / \mathrm{a}$, is comparable to that of the $\mathrm{K}$ area. From the Ir concentrations in filtered fractions of the Greenland ice core, the accretion rate at around $1908 \mathrm{AD}$ is estimated as $(10000 \pm 2000) \times 10^{3} \mathrm{~kg} / \mathrm{a}$ (Rasmussen et al., 1995). Although the method for determining the accretion rate is different from that used in the present study, these results are comparable to ours. This implies that the accretion rate of extraterrestrial materials to the Earth has been approximately constant from 27-33 kyr BP to the present.

5.2.2 Evaporated portion of influx of extraterrestrial materials As described above, the present influx of interplanetary dust has been reported to be $(40000 \pm 20000) \times$ $10^{3} \mathrm{~kg} / \mathrm{a}$ (Love and Brownlee, 1993). The accretion rates obtained in this study are about a third of this influx. Taylor $e t$ al. (1998) suggested that the difference in the accretion rates between their data, $(2700 \pm 1400) \times 10^{3} \mathrm{~kg} / \mathrm{a}$, and the influx calculated by Love and Brownlee could be due to evaporation occurring during atmospheric entry. Recently, the fraction of extraterrestrial material evaporated during atmo- 


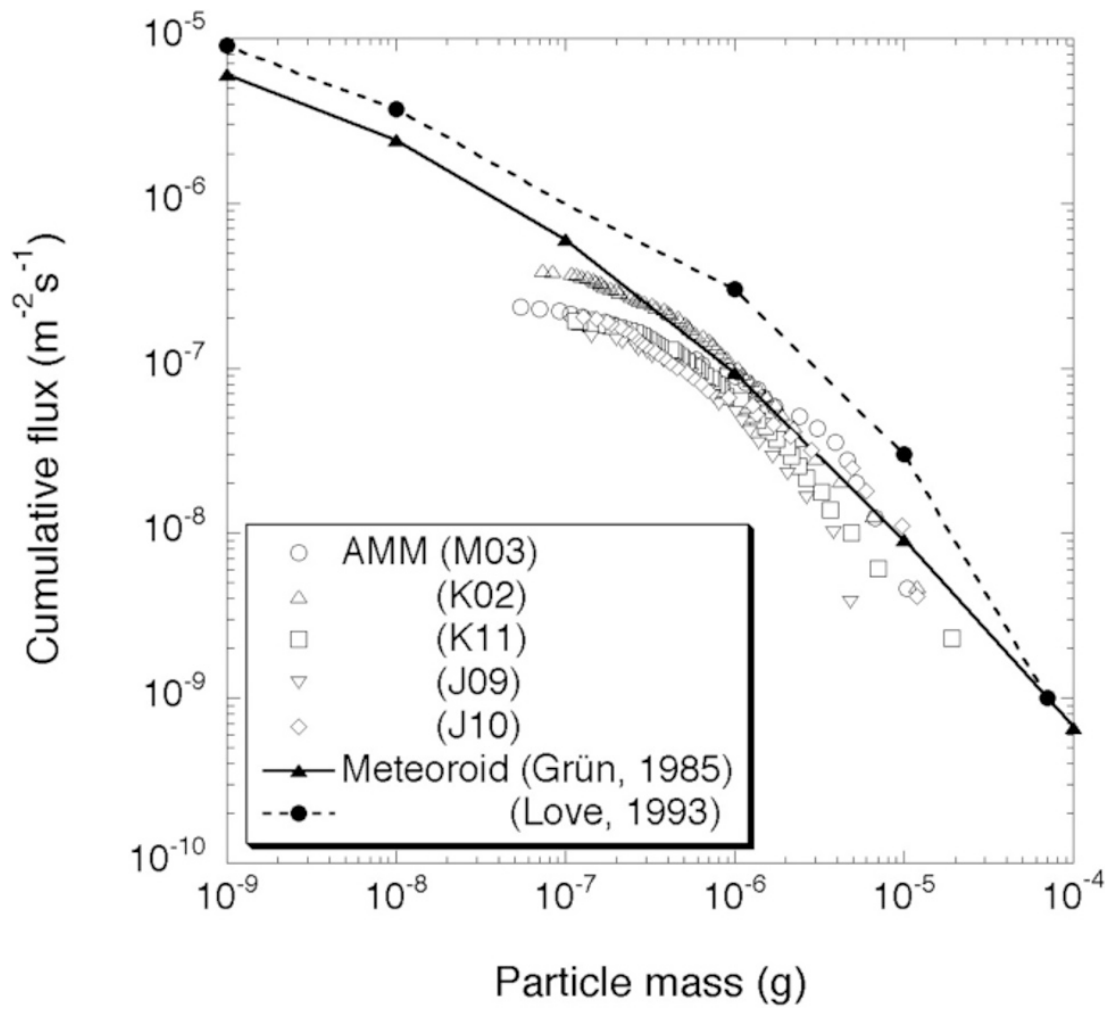

Fig. 6. Cumulative flux as a function of particle mass. The fluxes obtained from handpicked AMMs from M03, K02, K11, J09 and J10 are compared with those of meteoroids by Grün et al. (1985) and Love and Brownlee (1993). The meteoroid flux of Grün et al. (1985) is based on a theoretical model of orbital evolution of interplanetary dust and that of Love and Brownlee (1993) is based on the density of hypervelocity impact craters found on the LDEF satellite.

spheric entry was estimated to be $(4000-19000) \times 10^{3} \mathrm{~kg} / \mathrm{a}$ based on the chemical analysis of stratospheric aerosol $(\mathrm{Cz}-$ iczo et al., 2001). The sum of this evaporation rate and the accretion rate obtained in the present study essentially agrees with the influx of interplanetary dust given by Love and Brownlee (1993) within the estimated errors. This also indicates that the evaporated portion of extraterrestrial dust, if recondensed, must exist either in a water-soluble state such as the stratospheric sulfate aerosols reported in $\mathrm{Cz}$ iczo et al. (2001), or as very fine grains in the glacier ice. Hunten et al. (1980) postulated that meteor vapor might condense as nanometer-sized meteoric dust in the thermal sink of the mesosphere, and Murphy et al. (1998) found its candidates: $>0.2 \mu \mathrm{m} \mathrm{Fe}$-rich aerosols at lower stratosphere that contained $\mathrm{Mg}, \mathrm{Na}, \mathrm{K}, \mathrm{Ca}, \mathrm{Cr}$ and $\mathrm{Ni}$. Rasmussen et al. (1995) deduced a global accretion rate of chondritic materials of $(10000 \pm 2000) \times 10^{3} \mathrm{~kg} / \mathrm{a}$, that is comparable to the values of our study, based on the Ir abundances in the Greenland ice core filtered with a $0.45 \mu \mathrm{m}$ Millipore filter. Thus the recondensates might be smaller than $0.45 \mu \mathrm{m}$. An Os and Ir isotopic study of deep-sea sediment (PeuckerEhrenbrink and Ravizza, 2000) suggests that an accretion rate of $(30000 \pm 15000) \times 10^{3} \mathrm{~kg} / \mathrm{a}$, almost the same as the total influx of extraterrestrial materials to the Earth. This indicates that the evaporated portion of extraterrestrial dust is indeed included in deep-sea sediment in some forms different from micrometeorites.

5.2.3 Implication from mass distribution of the accretion rate Figure 6 plots the cumulative meteoroid flux vs. particle mass, in which the present data obtained from handpicked AMMs are compared to the data of Grün et al. (1985) and Love and Brownlee (1993). The slope of the line indicates the mass distribution of particles. The cumulative flux of AMMs in M03, K02, K11 and J10 roughly overlap in the mass range heavier than $10^{-6} \mathrm{~g}$, or $>100 \mu \mathrm{m}$ in diameter, but the slope generally decreases for $<10^{-6} \mathrm{~g}$. The cumulative flux of $\mathrm{K} 02$ is a little larger than those of the other four samples and is similar to that of Grün et al. (1985). This indicates that AMMs in K02 have been recovered effectively by handpicking for $>50 \mu \mathrm{m}$ in diameter, whereas considerable fractions of AMMs in the M03, K11, J09 and J10 have not been recovered by handpicking for particles $<100 \mu \mathrm{m}$ in diameter. This trend is consistent with relatively high contents of AMMs in the residues of M03 and K11 relative to that of $\mathrm{K} 02$.

There are a few estimates of the accumulation rate of micrometeorites collected from polar glacier ice. One is a value estimated from unmelted micrometeorites and cosmic spherules separated from sediments of Greenland ice combined with analysis of their Ir content, which gives $>4100 \times$ $10^{3} \mathrm{~kg} / \mathrm{a}$ in the last 2000 years (Maurette et al., 1987). The other is the present accretion rate, $(2700 \pm 1400) \times 10^{3} \mathrm{~kg} / \mathrm{a}$, which is evaluated from the number of cosmic spherules found in sediments in the water well at the South Pole Station (Taylor et al., 1998). The former value is only a third and the latter only a fifth of the values determined for the $\mathrm{K}$ area at 27-33 kyr BP.

Figure 7 shows various estimates of the micrometeorite 


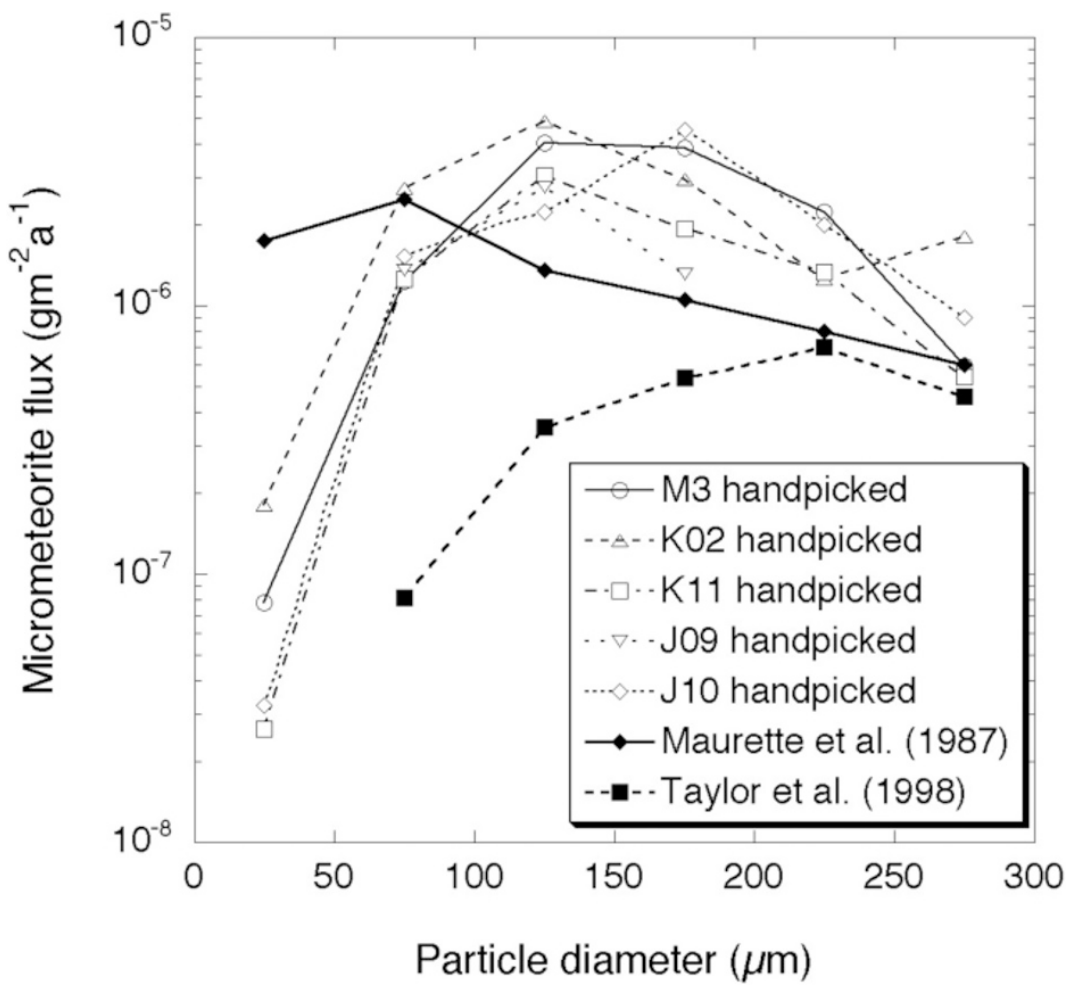

Fig. 7. Size distributions of micrometeorite flux. Each point represents the flux for a $50 \mu \mathrm{m}$ width of particle diameters. Fluxes of handpicked AMMs from the present study are compared with those of Maurette et al. (1987) and Taylor et al. (1998). The size distribution of micrometeorites in Maurette et al. (1987) was deduced from both handpicking of sediments found on the blue ice of Greenland and Ir analyses of the sediments. The distribution of Taylor et al. (1998) was obtained from spherules handpicked from sediments at the bottom of the water well at the South Pole Station.

flux vs. size using a 50- $\mu \mathrm{m}$ bin width; the estimates for the five samples studied here are compared with the data of Maurette et al. (1987) and Taylor et al. (1998). The distributions obtained in the present study are similar to each other, with peaks at 100-200 $\mu \mathrm{m}$ and extremely low fluxes for grains for $<50 \mu \mathrm{m}$. The distribution of Taylor et al. (1998), in contrast, shows a peak at 200-250 $\mu \mathrm{m}$ with a gradual decrease toward smaller grains. The difference is understandable, however, because their data are based only on cosmic spherules, i.e., completely melted AMMs. Smaller interplanetary dust particles would have less frictional heating during atmospheric entry, and would tend to survive as unmelted AMMs. Therefore, if a flux of unmelted AMMs is added, the data of Taylor et al. (1998) should come closer to the present results.

The distribution of Maurette et al. (1987) is different from that of our study; its peak is at $50-100 \mu \mathrm{m}$ size fraction with the $<50 \mu \mathrm{m}$ size fraction coming next. This may result from differences in the procedure used to deduce the size distribution of samples. Their AMMs distribution for the $<50 \mu \mathrm{m}$ size fraction was based on Ir abundances and that of the $>50 \mu \mathrm{m}$ fraction was based on handpicked chondritic spherules and Ir contents of the residue after handpicking. Their samples were deposits recovered from small ponds, which they called "cryoconite", on the blue ice in the Greenland; thus, they might have suffered less loss of extraterrestrial material in the $<50 \mu \mathrm{m}$ size fraction than the present study. Their global accretion rate of extraterrestrial materials is, however, lower than that of the present study $\left(>4100 \times 10^{3} \mathrm{~kg} / \mathrm{a}\right)$. One of the possible reasons is that their estimation for sedimentation age of the cryoconite might be overestimated.

\section{Conclusions}

The accretion rate of micrometeorites to the Earth in the last glacial period has been determined from the concentration of AMMs collected from blue ice around Yamato Mts., East Antarctica. The weight of AMMs contained in the blue ice was estimated from the weight of AMMs recovered by handpicking from the glacial sands and those in the residues estimated by solar Ne concentrations. The estimated abundances of AMMs in the residues are higher than those of the handpicked AMMs, suggesting that estimates of the former are essential for obtaining correct evaluations of the accretion rate of AMMs to the Earth. The obtained accretion rates are $(16000 \pm 9300) \times 10^{3} \mathrm{~kg} / \mathrm{a},(16000 \pm 9100) \times 10^{3} \mathrm{~kg} / \mathrm{a}$ $(11000 \pm 6600) \times 10^{3} \mathrm{~kg} / \mathrm{a},(5300 \pm 3100) \times 10^{3} \mathrm{~kg} / \mathrm{a}$ and $(7900 \pm 4800) \times 10^{3} \mathrm{~kg} / \mathrm{a}$ for M03, K02, K11, J09 and J10 sampling points, respectively. The values for J09 and J10 should be considered lower limits, because solar noble gases might have been partially lost from these samples due to aqueous alteration during long residence in the glacial ice. The accretion rate of AMMs around 27-33 kyr BP obtained for the $\mathrm{K}$ area ranges between $(11000 \pm 6600) \times 10^{3} \mathrm{~kg} / \mathrm{a}$ and $(16000 \pm 9100) \times 10^{3} \mathrm{~kg} / \mathrm{a}$, and that for the $\mathrm{M}$ area is similar. The estimated accretion rates are almost the same as estimates of the present accretion rate. This indicates that the influx of extraterrestrial dust onto the Earth has been nearly constant since the last glacial period. The present results for the AMM flux, $14000 \times 10^{3} \mathrm{~kg} / \mathrm{a}$ on average, together with the evaporated portion of the extraterrestrial material flux es- 
timated by stratospheric aerosol, $(4000-19000) \times 10^{3} \mathrm{~kg} / \mathrm{a}$, give a value nearly comparable to the estimated total influx of extraterrestrial dust to the Earth, $(40000 \pm 20000) \times 10^{3} \mathrm{~kg} / \mathrm{a}$, within errors. The evaporated extraterrestrial materials may exist as very fine grains $(<0.45 \mu \mathrm{m})$, which cannot be recovered by filtering of melted glacial ice.

Acknowledgments. This study is indebted to the members of JARE-39 for collecting the AMMs samples; and is supported by the Japanese AMM research team, I. Nakai, K. Nagao, H. Hiyagon, N. Imae, T. Fukuoka, K. Nogami, H. Ohashi, T. Murakami, R. Ohmori, W. Nozaki, T. Osawa, S. Mizutani, N. Matsumoto, J. Kamata, T. Mori, M. Sasaki, M. Itabashi and T. Setoyanagi. We are very grateful to Prof. Yoshiyuki Fujii in NIPR, for much valuable advice about glaciology. We express special thanks to Dr. Minoru Sekiya in Kyushu Univ. for discussions about this study, and Dr. Susan Taylor in U.S. Army Cold Regions Research and Engineering Laboratory for helpful comments. We are grateful to Dr. Christine Floss of Washington University in St. Louis for help with the English. Thoughtful reviews by Dr. Michael E. Zolensky and an anonymous reviewer are greatly appreciated, and led to considerable improvements of this paper. We thank the Antarctic Meteorite Research Center of NIPR for use of analytical machines and facilities. This study is partially supported by the Research Fellowships of the Japan Society for the Promotion of Science for Young Scientists, given to T.Y., by the research fund of NIPR, by the cooperative program of the Institute for Cosmic Ray Research, University of Tokyo, and by the Scientific Research Grant-in-Aid of the Ministry of Education, Culture, Sports, Science and Technology (No 11440163 to H.K. and No. 13740318 to T.N.).

\section{Appendix A. Description of Inland Blue Ice Areas in Antarctica and Comments on AMM Concentrations}

In the inland snow accumulation areas of Antarctica, compressed snow becomes glacier ice. The glacier ice formed in the inland usually flows down toward the shore and finally become icebergs when it reaches the ocean. However, if there are mountains blocking the ice flow, the glacier ice rises in the front of the mountains and is consumed by wind and sunshine to form blue ice areas (Yanai, 1978; Cassidy et al., 1992; Bintanja, 1999).

In blue ice areas at an altitude lower than $1000 \mathrm{~m}$, such as Cap Prudohomme near the Dumond d'Urville Station, some concentrations of micrometeorites have been reported (Maurette et al., 1994; Gounelle et al., 1999; Maurette et al., 2000). These concentrations are favorable for collecting AMMs, but it is impossible to estimate the accretion rate of micrometeorites, because the distribution of AMMs in the blue ice was disturbed.

Such concentrations of AMMs may occur in two ways. In the lower altitude blue ice areas, cryoconite holes, which are round-shaped transparent patches of ice, occur due to absorption of solar radiation by a stone (Bintanja, 1999). With this process, a small black particle such as a micrometeorite should sink to the glacial ice and stay at a certain depth below the ice surface where the heat given by solar radiation balances the conductive heat loss from the particle. Thus AMMs showed concentrate at a certain depth from the surface of ice. However, no cryoconite holes have been reported in high altitude blue ice areas, such as the blue ice area of the Yamato Mts. studied here, which is located 2000-2300 m above sea level (Bintanja, 1999).

In high altitude blue ice areas, micrometeorites would be blown by a strong katabatic wind and are concentrated among moraine sand where the wind is weakened due to geomorphic conditions (Koerberl and Hagen, 1989; Harvey and Maurette, 1991). However, sampling areas of AMMs in the present study were in clear blue ice fields at least $2 \mathrm{~km}$ windward from the nearest moraine, where such a concentration of AMMs due to wind transportation should not occur. Consequently, we conclude that no AMM concentration process would have occurred at the sampling areas of the present study.

\section{References}

Azuma, N., M. Nakawo, A. Higashi, and F. Nishio, Flow pattern near massif A in the Yamato bare ice field estimated from the structures and the mechanical properties of a shallow ice core, Mem. Natl Inst. Polar Res. Spec. Issue 39, 173-183, 1985

Bender, M., T. Sowers, M.-L. Dickson, J. Orchardo, P. Grootes, P. A Mayewski, and D. A. Meese, Climate correlations between Greenland and Antarctica during the past 100,000 years, Nature, 372, 663-666, 1994.

Benkert, J.-P., H. Baur, P. Signer, and R. Wieler, He, Ne, Ar from the solar wind and solar energetic particles in lunar ilmenites and pyroxenes, $J$. Geophys. Res., 98, 13147-131162, 1993.

Bintanja, R., On the glaciological, meteorological, and climatological significance of Antarctic blue areas, Rev. Geophys., 37, 337-359, 1999.

Bland, P. A., T. B. Smith, A. J. T. Jull, F. J. Berry, A. W. R. Bevan, S. Cloudt, and, C. T. Pillinger, The flux of meteorites to the Earth over the last 50000 years, Mon. Not. R. Astron. Soc., 283, 551-565, 1996.

Caillon, N., J. P. Severinghaus, J.-M. Barnola, J. Chappellaz, J. Jouzel, and F. Parrenin, Eastimation of temperature change and of gas age-ice age difference, 108 kyr B.P., at Vostok, Antarctica, J. Geophys. Res., 106 31893-31901, 2001.

Cassidy, W., R. Harvey, J. Schutt, G. Delisle, and K. Yanai, The meteorite collection sites of Antarctica, Meteoritics, 27, 490-525, 1992.

Cziczo, D. J., D. S. Thomson, and D. M. Murphy, Ablation, flux, and atmospheric implications of meteors inferred from stratospheric aerosol, Science, 291, 1772-1775, 2001.

Eberhardt, P., J. Geiss, and N. Grögler, Further evidence of the origin of trapped gases in the meteorite Khor Temiki, J. Geophys. Res., 70, 43754378,1965 .

Engrand, C. and M. Maurette, Carbonaceous micrometeorites from Antarctica, Meteoritics Planet. Sci., 33, 565-580, 1998.

Eugster, O., Cosmic-ray production rates for ${ }^{3} \mathrm{He},{ }^{21} \mathrm{Ne},{ }^{38} \mathrm{Ar},{ }^{83} \mathrm{Kr}$, and ${ }^{126} \mathrm{Xe}$ in chondrites based on ${ }^{81} \mathrm{Kr}-\mathrm{Kr}$ exposure ages, Geochim. Cos mochim. Acta, 52, 1649-1662, 1988

Gounelle, M., M. Maurette, G. Kurat, and C. Hammer, Comparison of the 1998 "Cap-Prudhomme" and "Astrolabe" Antarctic micrometeorite collections with the 1996 "South Pole" collection: Preliminary implication, in Lunar Planet. Sci. XXX, Abstract \#1564, Lunar and Planetary Institute, Houston (CD-ROM), 1999

Grün, E., H. A. Zook, H. Fechtig, and R. H. Giese, Collisional balance of the meteoritic complex, Icarus, 62, 244-272, 1985

Harvey, R. P. and M. Maurette, The origin and significance of cosmic dust from the Walcott Névé, Antarctica, Proc. Lunar Planet. Sci., 21, pp. 569578,1991

Hunten, D. M., R. P. Turco, and O. B. Toon, Smoke and dust particles of meteoritic origin in the mesosphere and stratosphere, J. Atmos. Sci., 37, 1342-1356, 1980

Iwata, N. and N. Imae, Antarctic micrometeorite collection at a bare ice region near Syowa Station by JARE-41 in 2000, Antarct. Meteorite Res. 15, 25-37, 2002

Koeberl, C. and E. H. Hagen, Extraterrestrial spherules in glacial sediment from the Transantarctic Mountains, Antarctica: Structure, mineralogy, and chemical composition, Geochim. Cosmochim. Acta, 53, 937-944, 1989.

Lever, J. H., S. Taylor, and R. Harvey, A collector to retrieve micrometeorites from the South Pole water well, in Lunar Planet. Sci., XXVII 747-748, Lunar and Planetary Institute, Houston, 1996.

Love, S. G. and D. E. Brownlee, A direct measurement of the terrestria mass accretion rate of cosmic dust, Science, 262, 550-553, 1993.

Machida, T., T. Nakazawa, H. Narita, Y. Fujii, S. Aoki, and O. Watanabe, Variations of the $\mathrm{CO}_{2}, \mathrm{CH}_{4}$ and $\mathrm{N}_{2} \mathrm{O}$ concentrations and $\delta^{13} \mathrm{C}$ of $\mathrm{CO}_{2}$ 
in the glacial period deduced from an Antarctic ice core, South Yamato, Proc. NIPR Sym. Polar Meteorol. Glaciol., 10, 55-65, 1996.

Maurette, M., C. Jéhanno, E. Robin, and C. Hammer, Characteristics and mass distribution of extraterrestrial dust from the Greenland ice cap, Nature, 328, 699-702, 1987.

Maurette, M., C. Olinger, M. C. Michel-Levy, G. Kurat, M. Pourchet, F. Brandstätter, and M. Bourat-Denise, A collection of diverse micrometeorites recovered from 100 tonnes of Antarctic blue ice, Nature, 351, 44-46, 1991.

Maurette, M., G. Immel, C. Hammer, R. Harvey, G. Kurat, and S. Taylor, Collection and curation of IDPs from the Greenland and Antarctic ice sheets, in Analysis of interplanetary dust, edited by M. E. Zolensky, T. L. Wilson, F. J. M. Rietmeijer, and G. J. Flynn, pp. 277-289, American Institute of Physics, New York, 1994.

Maurette, M., J. Duprat, C. Engrand, M. Gounelle, G. Kurat, G. Matrajt, and A. Toppani, Accretion of neon, organics, $\mathrm{CO}_{2}$, nitrogen and water from large interplanetary dust particles on the early Earth, Planet. Space Sci., 48, 1117-1137, 2000.

Murphy, D. M., D. S. Thomson, and M. J. Mahoney, In situ measurements of organics, meteoritic material, mercury, and other elements in aerosols at 5 to 19 kilometers, Science, 282, 1664-1669, 1998.

Nakamura, T. and N. Takaoka, Solar-wind derived light noble gases in micrometeorites collected at the Dome Fuji Station: Characterization by stepped pyrolysis, Antarct. Meteorite Res., 13, 311-321, 2000.

Nakamura, T., N. Imae, I. Nakai, T. Noguchi, H. Yano, K. Terada, T. Murakami, T. Fukuoka, K. Nogami, H. Ohashi, W. Nozaki, M. Hashimoto, N. Kondo, H. Matsuzaki, O. Ichikawa, and R. Ohmori, Antarctic micrometeorites collected at the Dome Fuji Station, Antarct. Meteorite Res., 12, 183-198, 1999.

Nakawo, M., M. Nagoshi, and S. Mae, A stratigraphic record of an ice core from the Yamato meteorite ice field, Antarctica, Ann. Glaciol., 10, 126129, 1988.

Nakazawa, T., T. Machida, K. Esumi, M. Tanaka, Y. Fujii, S. Aoki, and O. Watanabe, Measurements of $\mathrm{CO}_{2}$ and $\mathrm{CH}_{4}$ concentrations in air in a polar ice, J. Glaciol., 39, 209-215, 1993.

National Institute of Polar Research, Antarctica-east Queen Maud LandEnderby Land Glaciological Folio, 1 pp., National Institute of Polar Research, Tokyo, 1997.

Nier, A. O. and J. Schlutter, The thermal history of interplanetary dust particles collected in the Earth's stratosphere, Meteoritics, 28, 675-681, 1993.

Nishibori, E. and M. Ishizaki, Meteoritic dust collected at Syowa Base, Ongul island, east coast of Lützow-Holm bay, Antarctica, Antarctic Record, 7, 35-38, 1959 (in Japanese with English abstract).

Noguchi, T., N. Imae, T. Nakamura, W. Nozaki, K. Terada, T. Mori, I. Nakai, N. Kondo, M. Sasaki, T. Murakami, T. Fukuoka, K. Nogami, R. Ohomori, and H. Ohashi, A consortium study of Antarctic micrometeorites recovered from the Dome Fuji station, Antarct. Meteorite Res., 13, 270-284, 2000 .

Osawa, T. and K. Nagao, Noble gas compositions of Antarctic micrometeorites collected at the Dome Fuji station in 1996 and 1997, Meteorit. Planet. Sci., 37, 911-936, 2002.

Ozima, M. and F. A. Podsek, Noble gas geochemistry, 286 pp., Cambridge University Press, Cambridge, 2002.

Parkin, D. W. and D. Tilles, Influx measurements of extraterrestrial material, Science, 159, 936-946, 1968.

Petit, J. R., J. Jouzel, D. Raynaud, N. I. Barkov, J.-M. Barnola, I. Basile, M. Bender, J. Chappellaz, M. Davis, G. Delaygue, M. Delmotte, V. M. Kotlyakov, M. Legrand, V. Y. Lipenkov, C. Lorious, L. Pépin, C. Ritz, E. Saltzman, and M. Stievenard, Climate and atmospheric history of the past 420,000 years from the Vostok ice core, Antarctica, Nature, 399 429-436, 1999.
Peucker-Ehrenbrink, B., Accretion of extraterrestrial matter during the last 80 million years and its effect on the marine osmium isotope record, Geochim. Cosmochim. Acta, 60, 3187-3196, 1996.

Peucker-Ehrenbrink, B. and G. Ravizza, The effects of sampling artifacts on cosmic dust flux estimates: A reevaluation of nonvolatile tracers (Os, Ir), Geochim. Cosmochim. Acta, 64, 1965-1970, 2000.

Rasmussen, K. L., H. B. Clausen, and G. W. Kallemeyn, No iridium anomaly after the 1908 Tunguska impact: Evidence from a Greenland ice core, Meteoritics, 30, 634-638, 1995.

Shima, M. and H. Yabuki, Study of the extraterrestrial material at Antarctica (I), Antarctic Record, 33, 53-64, 1968 (in Japanese with English abstract).

Takayanagi, M. and M. Ozima, Temporal variation of ${ }^{3} \mathrm{He} /{ }^{4} \mathrm{He}$ ratio recorded in deep-sea sediment cores, J. Geophys. Res., 92, 12531-12538, 1987.

Taylor, S., J. H. Lever, and R. P. Harvey, Accretion rate of cosmic spherules measured at the South Pole, Nature, 392, 899-903, 1998.

Taylor, S., J. H. Lever, and R. P. Harvey, Numbers, types, and compositions of an unbiased collection of cosmic spherules, Meteoritics Planet. Sci., 35, 651-666, 2000.

Tazawa, Y. and Y. Fujii, New types of spherules from Antarctica: meteoritic impact origin?, Geophys. Res. Lett., 14, 1199-1202, 1987.

Terada, K., T. Yada, H. Kojima, T. Noguchi, T. Nakamura, T. Murakami, H. Yano, W. Nozaki, Y. Nakamuta, N. Matsumoto, J. Kamata, T. Mori, I. Nakai, M. Sasaki, M. Itabashi, T. Setoyanagi, K. Nagao, T. Osawa, H. Hiyagon, S. Mizutani, T. Fukuoka, K. Nogami, R. Ohmori, and H. Ohashi, General characterization of Antarctic micrometeorites collected by the 39th Japanese Antarctic Research Expedition: Consortium studies of JARE AMMs (III), Antarct. Meteorite Res., 14, 89-107, 2001.

Watanabe, O., K. Kamiyama, H. Motoyama, Y. Fujii, H. Shoji, and K. Satow, The paleoclimate record in the ice core at Dome Fuji station, East Antarctica, Ann. Glaciol., 29, 176-178, 1999a.

Watanabe, O., Y. Fujii, K. Kamiyama, H. Motoyama, T. Furukawa, M. Igarashi, M. Kohno, S. Kanamori, Y. Ageta, M. Nakawo, H. Tanaka, K. Satow, H. Shoji, K. Kawamura, S. Matoba, and W. Shimada, Basic analyses of Dome Fuji deep ice core part 1: Stable oxygen and hydrogen isotope ratios, major chemical compositions and dust concentration, Polar Meteorol. Glaciol., 13, 83-89, 1999 b.

Wetherill, G. W., Where do the meteorites come from? A re-evaluation of the Earth-crossing Apollo objects as sources of chondritic meteorites, Geochim. Cosmochim. Acta, 40, 1297-1317, 1976.

Wieler, R., H. Baur, J.-P. Benkert, A. Pedroni, and P. Signer, Noble gases in the meteorite Fayetteville and in lunar ilmenite originating from solar energetic particles (abstract), Lunar Planet. Sci., 18, 1080-1081, 1987.

Yada, T. and H. Kojima, The collection of micrometeorites collected in the Yamato Meteorite Ice Field of Antarctica in 1998, Antarct. Meteorite Res., 13, 9-18, 2000.

Yanai, K., Yamato-74 meteorites collection, Antarctica from November to December 1974, Mem. Natl. Inst. Polar Res., Spec. Issue 8, 1-37, 1978.

Yiou, F. and G. M. Raisbeck, Cosmic spherules from an Antarctic ice core, Meteoritics, 22, 539-540, 1987.

Yiou, F., G. M. Raisbeck, and C. Jéhanno, Influx of cosmic spherules to the Earth during the last $\sim 10^{5}$ years as deduced from concentrations in Antarctica ice cores, Meteoritics, 24, 344 (abstr.), 1989.

Zolensky, M. E., A. Pun, and K. L. Thomas, Titanium carbide and titania phases in Antarctic ice particles of probable extraterrestrial origin, Proc. 19th Lunar Planet. Sci. Conf., Lunar and Planetary Institute, Houston, pp. 505-511, 1989.

T. Yada (e-mail: tyada@physics.wustl.edu), T. Nakamura, N. Takaoka, T. Noguchi, K. Terada, H. Yano, T. Nakazawa, and H. Kojima 